\title{
New description for the bright, dark periodic solutions to the complex Hirota-dynamical model
}

\author{
Ahmet Bekir ${ }^{1}$ and Emad Zahran ${ }^{2}$ \\ ${ }^{1}$ Eskisehir \\ ${ }^{2}$ Benha University
}

July 30, 2020

\begin{abstract}
In this article, we employ the nonlinear complex Hirota-dynamical model which is one of the famous and important standards to the nonlinear Schrödinger equation in which the third derivative term represent the self-interaction in the high-frequency subsystem. Specially, in plasma this term is isomorphic to the so known self-focusing effect. The bright, dark and periodic optical soliton solutions to this equation will realized successfully for the first time in the framework of the solitary wave ansatz method. Furthermore, in this connection at the same time and parallel the extended simple equation method has been applied successfully to achieve new impressive solitary wave solutions to this model. A comparison between the obtained results and that satisfied in previous work has been established.
\end{abstract}

\section{Hosted file}

MMAS.pdf available at https://authorea.com/users/327788/articles/473199-new-description-forthe-bright-dark-periodic-solutions-to-the-complex-hirota-dynamical-model
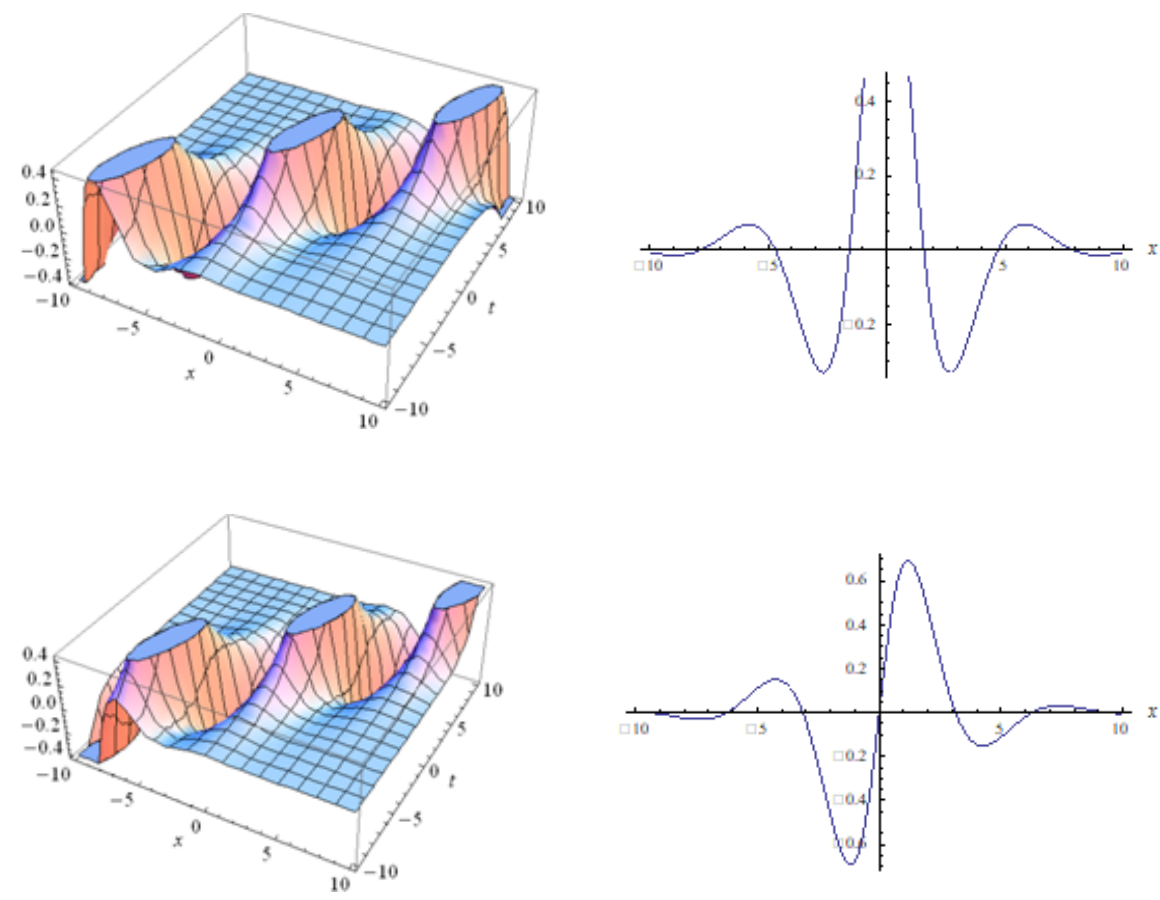

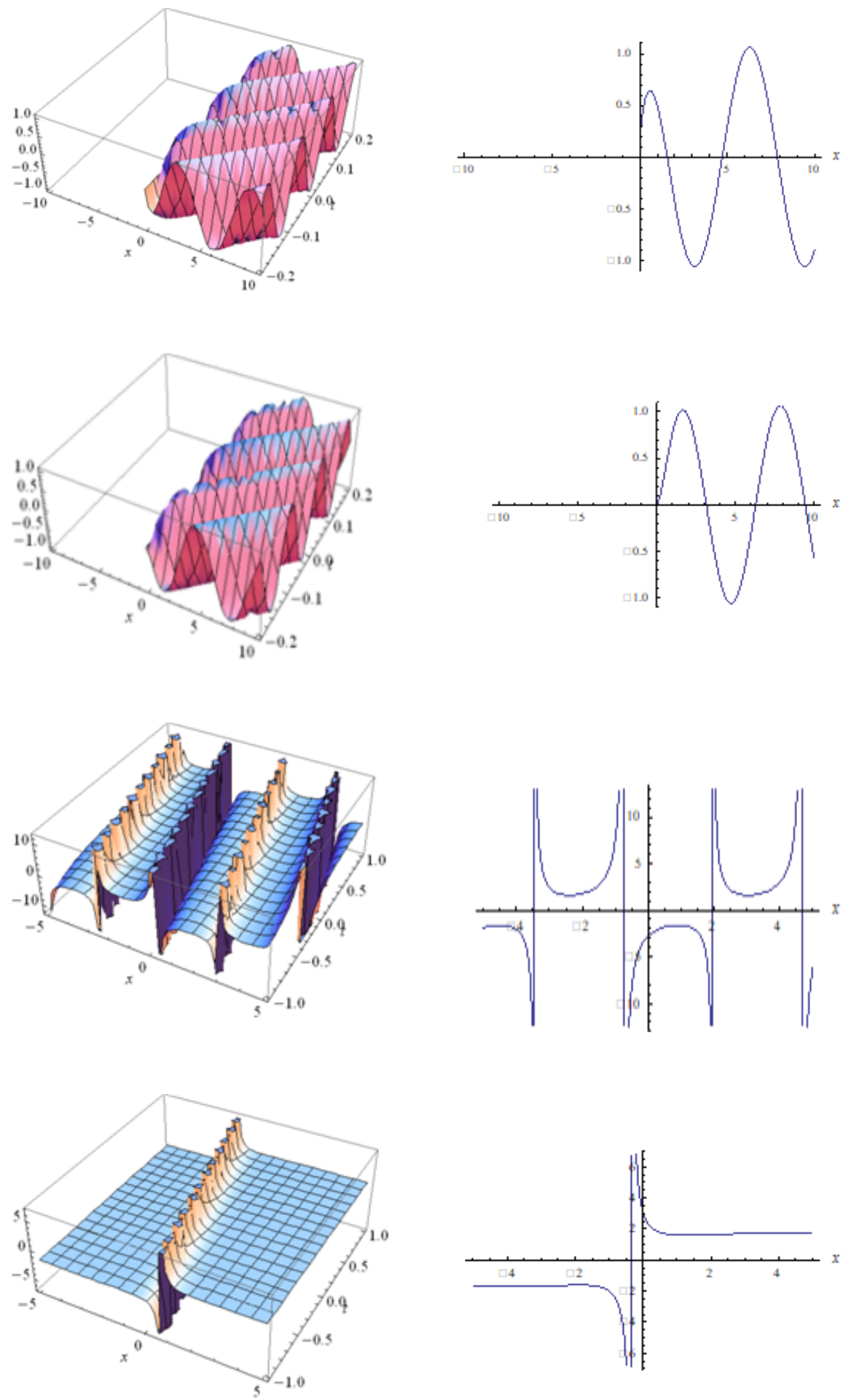

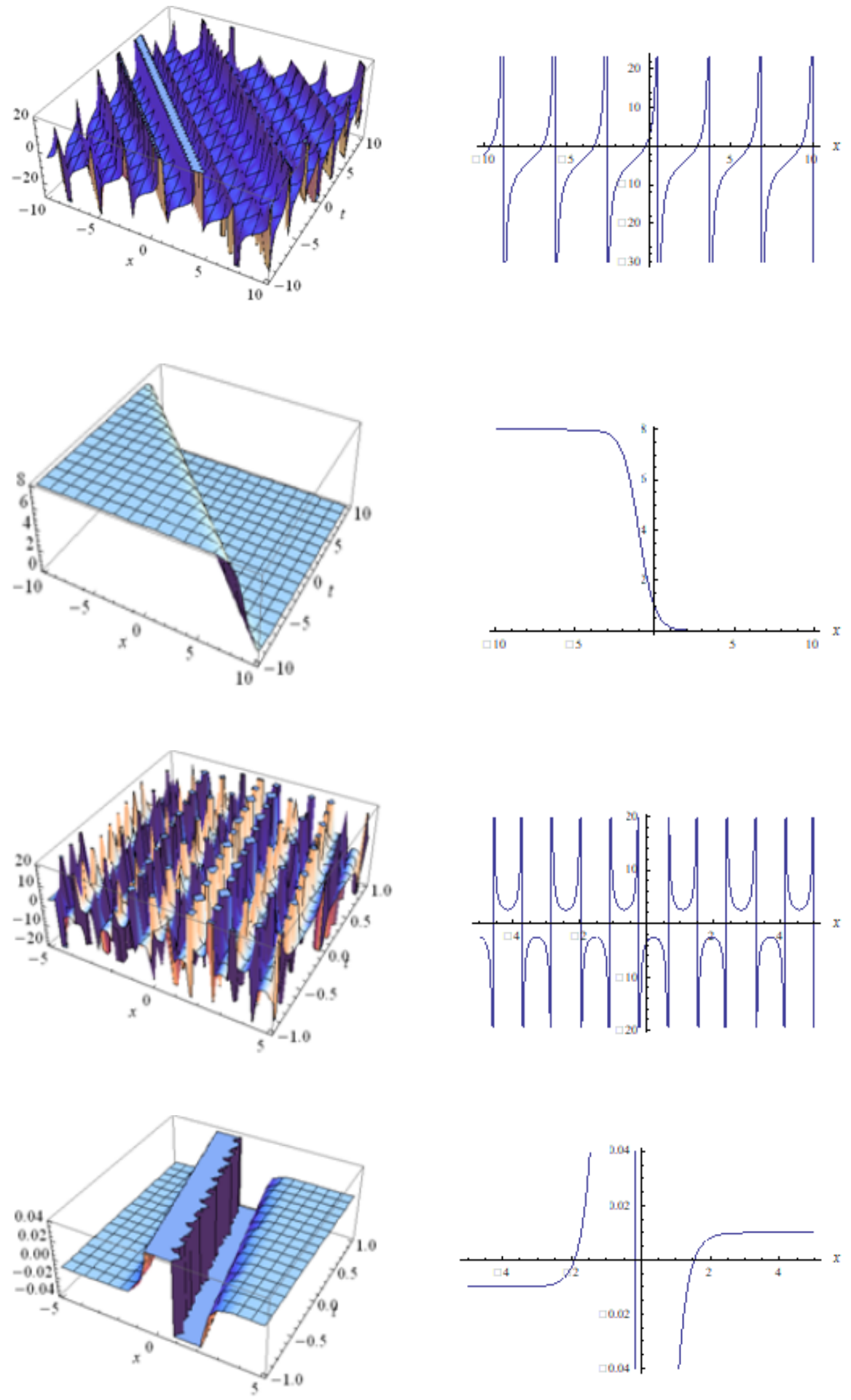

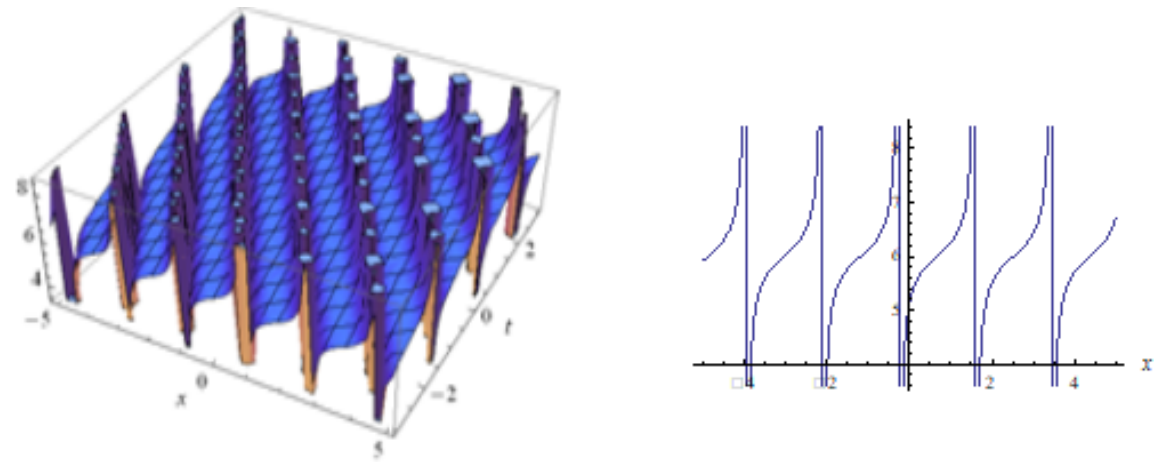